\title{
Performance Evaluation of Radon Mitigating Materials for Building a Radon Resistant Dwelling
}

\author{
${ }^{1}$ Young Sub Lee, ${ }^{2}$ Yong Hee Lee, ${ }^{3}$ Yong Cheol Kim, ${ }^{4}$ Gyu-Sik Kim \\ ${ }^{1,2} \mathrm{C} \& \mathrm{H}$, Inc., ${ }^{3,4}$ Department of Electrical and Computer Eng \\ ${ }^{1,2} \# 1505$ Gangnam-daero 320, Gangnam-gu, Seoul, Korea ${ }^{3,4}$ University of Seoul, Seoul, Korea
}

Abstract-- Radon mitigation performance of SGMs and ARMs was evaluated in five different modes, two of which are active modes supported by a ventilation fan on and the others are passive modes with no fan. The test was performed in a concrete structure consisting of eight partitioned rooms. The bottom side of each room is covered with gravels and radon gas soil sampled at nearby open fields. Then, SGMs and ARMs are installed on top of the soil to block the radon gas. The test is performed for three days in passive modes and for another three days in active modes. Then, the radon concentration is measured with an E-perm monitor. These tests are repeated for three different levels of radon gas concentration in the sample soil, labeled as low (L), medium (M) and high $(\mathrm{H})$. Experimental results present two observations. The first one is that, in accordance with the EPA recommendations, radon mitigating materials make much greater effects when they are used in an active mode. The best result was from A-1 mode (SGM+ARM+fan). For all of $\mathrm{L}, \mathrm{M}$ and $\mathrm{H}$ soil samples, the radon concentration turned out to be the lowest, about $10 \% \sim 40 \%$ of $148 \mathrm{~Bq} / \mathrm{m}^{3}$, the EPA activation level (EAL). In A-2 mode (SGM+ fan), the concentration was a reasonably fair level, about $25 \%$ $\sim 48 \%$ of EAL. The second observation is that the performance of mitigating materials used in passive modes is unreliable. In all of three passive test modes, the radon concentration was higher than the EAL, or just below the EAL.

Index Terms-- Radon mitigation, SGM, ARM, EPA, fan

\section{INTRODUCTION}

Radon is a naturally occurring radioactive gas. It originates from the decay of uranium, which is present in small quantities in all rocks and soils. It is colorless, odorless and tasteless and can only be measured using special equipment. Because it is a gas, radon can move freely through the soil enabling it to enter the atmosphere. When radon surfaces in the open air, it is quickly diluted to harmless concentrations, but when it enters an enclosed space, such as a house, it can sometimes accumulate to unacceptably high concentrations. So, measurements of indoor radon are very important for escaping from radon risks.

In the past twenty years, assessments of radon concentration in indoor air have been extensively conducted for the dwellings, offices and schools around the world ${ }^{(1-12)}$.

There have been a lot of research works toward reducing of indoor radon levels. A fan was mounted in a kindergarten to ventilate a sub-floor channel for 20 minutes three times every day to reduce radon level to an acceptable value ${ }^{(13)}$. The Enkavent mat method and the suction pit method are applied to reduce radon entry in new homes in the city of Gainesville, Florida, USA (14). The cost of mitigating radon levels in domestic properties was examined using data from the radon-affected county of Northamptonshire, UK ${ }^{(15)}$. The pilot study suggested that the radon-proof membranes currently incorporated in new houses constructed in the UK did not always provide adequate radon protection ${ }^{(16)}$. The health benefits and costeffectiveness of the radon remediation program were evaluated in domestic properties in Northamptonshire, UK ${ }^{(17)}$. Active systems such as radon sumps and fan assisted under-floor ventilation were proved to be effective for radon remediation in Irish schools ${ }^{(18)}$. The 
cost-effectiveness of radon-proof membranes was studied in new homes in the village of Brixworth, Northamptonshire, UK ${ }^{(19)}$. The effectiveness of soil ventilation systems for reducing radon risk was studied in single-family Minnesota homes ${ }^{(20)}$. The real situation of indoor radon gas in Korea was described and governmental actions were presented ${ }^{(21)}$.

U.S. Environmental Protection Agency (EPA) provides a list of recommendations of radon reduction methods in constructing a new building. Popular approaches are sub-slab depressurization and submembrane depressurization. Because the air pressure in the interior of a building is usually lower than the pressure in the surrounding soil, radon vapors may be drawn into the building. Depressurization lowers the pressure under the foundation of the building. Usually gases are vented in an active mode by a fan-powered drawing air from beneath the slab. According to EPA documents, in virtually all homes with an active system, the radon levels are below $148 \mathrm{~Bq} / \mathrm{m}^{3}$.

When the potential vapor intrusion is minor, the ventilation may be operated in a passive mode. In this case, with electric fans off, the ventilation depends just on the natural air flow around the outlet of the venting pipes. The reliability of a passive system is lower and the performance of ventilation is somewhat unpredictable because outdoor air pressure, which is the driving force of providing a negative pressure, is always changing. A merit of a passive system is that it is fully functioning as soon as the building is constructed. It is cost effective since it does not require any energy.

Several materials can be used to block the soil radon gas and reduce the radon concentration of the indoor air. Among them, soil gas mats (SGM) and anti-radon membranes (ARM) are widely used, due to easy installation. A SGM and an ARM can effectively protect the indoor air as they function as vapor barriers placed below the slab of the building ${ }^{(22)}$.

In this paper, we present the results of performance evaluation of radon reduction of a SGM and an ARM. The test was performed in a concrete structure which consists of eight partitioned rooms. The bottom side of each room is covered by radon gas soil sampled at nearby open fields. Then, we install SGMs and ARMs on top of the soil to protect the indoor air. We measure the radon concentration of air in test rooms of concrete structure.
For comparison of radon reduction efficiency, SGMs and ARMs are deployed in five different modes, two of which are active modes and the others are passive modes. Tests are repeated for three different levels of radon concentration in the sample soil gas. They are labeled as low (L), medium (M) and high (H) concentration. The results of this study will be used as the experimental data for establishing a domestic RRNC.

\section{EXPERIMENTAL SETUP}

The test location is at $80 \mathrm{~km}$ southeast of Seoul, the capital city of South Korea. The geographic coordinates are N36.9603262 and E127.4676599. The soil components are coarse granite and quaternary alluvium. The temperature range was from $14^{\circ} \mathrm{C}$ to $29^{\circ} \mathrm{C}$ in August, 2016, which is the test period ${ }^{(22)}$.

The radon concentration of indoor air of test rooms was measured by an E-perm electret monitor. During the exposure period, the charges in the electrets in an E-perm chamber continue to deplete with the negative ions generated from decaying of radon particles in the atmosphere. The decrease of charges is measured by reading the electric voltage of the electrets before and after the exposure. The voltage difference corresponds to the radon concentration of the atmosphere. We used an S-type (short-term) E-perm electret radon monitor (Rad Elec Inc., USA), which is designed for shortterm tests of 48 hours to 10 days.

When a house is built on slab-on-grade or basement foundation, the radon gas should be able to move laterally beneath the slab to the location where the vent pipe collects the radon gas. A SGM helps to collect soil gas collection beneath slabs. A SGM consists of interconnected strips of drainage mats which are laid on top of the soil sub-grade and beneath the slab. Drain mats are made of plastic material of sufficient permeability beneath concrete floors to allow for the capture and exhaust of naturally occurring radon gas. Usually, SGMs are installed in a form of a loop of matting inside the exterior perimeter foundation walls.

An ARM protects the building from the ingress of radon gas into the property. ARMs are made of polymer films of low permeability which can prevent the ingress of radon gas from entering into the interior of buildings. Covering the entire footprint of the floor area, it provides a sealing between the gas permeable layer and the concrete slab. The sheeting can act as a 
vapor barrier to reduce moisture and other soil gas entry into the home.

The model number of the electric ventilation fan used in this study is GP501, manufactured by RadonAway, USA. In order to evaluate the performance of radon mitigating materials such as a SGM, an ARM and a radon fan, a model house was constructed. The radon concentration of the soil gas in the model house and the surrounding area was $58.49 \mathrm{kBq} / \mathrm{m}^{3}$. The radon concentration was measured using RAD7 after digging into the ground with a depth of $70 \mathrm{~cm}$. The model house consists of eight separate rooms whose dimensions are $1 \mathrm{~m}$ long, $1 \mathrm{~m}$ wide and $2 \mathrm{~m}$ high. The dimension of the substructure of each room is $1 \mathrm{~m}$ long, $1 \mathrm{~m}$ wide and $0.7 \mathrm{~m}$ high. The substructure consists of three layers. The lowest one was covered with pebbles. The middle one was for sample soil. The radon mitigating materials were installed on the top of the substructure. Walls, doors, ceilings and roofs were made of sandwich panels. All of the joints were sealed tightly.

The layout of the installation of radon mitigating materials in each of the eight rooms is shown in Fig. 1.
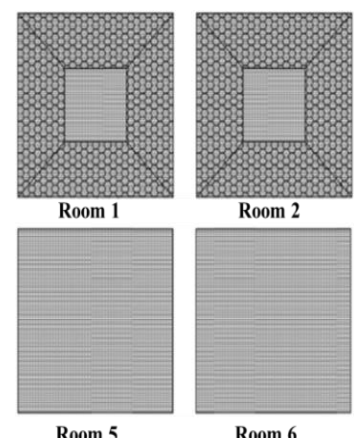

Room 6
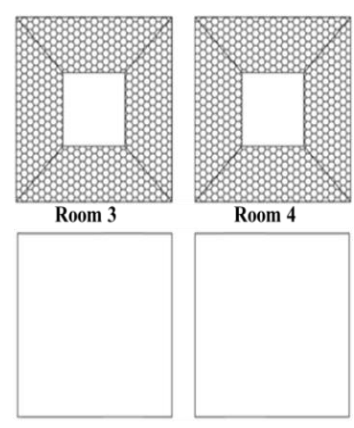

Room 7

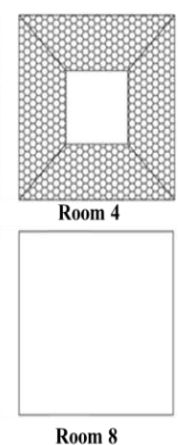

Room 8
Figure 1: Installation examples of radonn mitigating materials

In room 1 and in room 2, SGMs, ARMs and a radon fan are installed. P-1 is label for the case with the radon fan off and A-1 is the label for the case with the radon fan on. In room 3 and in room 4, SGMs and a radon fan are installed. P-2 is the label for case with the radon fan off and A-2 is the label for the case with the radon fan on. In room 5 and in room 6 , ARMs are installed and the label is P-3. In room 7 and in room 8, no radon mitigating materials are installed and the label is 'Unprotected'. Each radon mitigating material is installed in two rooms so that we can reduce the interference between rooms and the deviation of concentration due to the difference of sample quantities.
The test of mitigation performance was performed in six modes as shown in Table 1. SGMs and ARMs are used as the radon mitigating materials. Test modes are classified into active modes and passive modes, depending on the use of a fan. Two rooms grouped in one set are tested in each mode. Tests were performed for seven days for each sample soil with low concentration, medium concentration and high concentration. An E-perm monitor was used for the measurement of radon concentration of each room. The final concentration value for each mode is the average of the concentration in two rooms.

Table 1: Six modes of radon reduction test

\begin{tabular}{|c|c|}
\hline Test mode & $\begin{array}{c}\text { Mitigating materials and } \\
\text { Fan }\end{array}$ \\
\hline A-1 (active) & SGM + ARM + Fan ON \\
\hline A-2 (active) & SGM + Fan ON \\
\hline P-1 (passive) & SGM + ARM + Fan OFF \\
\hline P-2 (passive) & SGM + Fan OFF \\
\hline P-3 (passive) & ARM only \\
\hline Unprotected & None \\
\hline
\end{tabular}

Samples of soil were taken at three neighboring locations in the test bed area, the radon concentrations of which are low $\left(3.40 \mathrm{kBq} / \mathrm{m}^{3}\right)$, medium (46.99 $\mathrm{kBq} / \mathrm{m}^{3}$ ) and high $\left(96.97 \mathrm{kBq} / \mathrm{m}^{3}\right.$ ), respectively (Table $2)$. The samples in three different concentrations are dried in natural air and then are used in the performance test of radon mitigating materials. Each sample is used for one week for each concentration. The total period is three weeks (2016. 8. 4 - 2016. 8 . 26). An E-perm monitor was used for the measurement of radon concentration. These E-perm monitors are installed and collected simultaneously in each room and then the analysis was performed. At first, we started the test after sprinkling of soil sample of low concentration in the substructure and the installation of radon mitigating materials. Cases with a radon fan on are referred to as active types and cases with a radon fan off are passive types. First, tests are performed in a passive type with a radon fan off for all the eight rooms (Room $1 \sim$ Room 8). We measured the radon concentration and obtained the test results for P-1, P-2, P-3 and the Unprotected. This test continued for three days. In succession, we performed 
tests in active modes with a radon fan on for 4 rooms (Room $1 \sim$ Room 4) and then measured the radon concentration and obtained the test results for A-1 and A-2. This test continued for three days, too. The radon fan was continuously on throughout the test period. Then, we took out the sample soil of low concentration for one day and then sample soil of medium concentration was sprinkled in the substructure. The same test procedure was performed. At last, an identical test was performed for the sample soil of high concentration.

Table 2: Soil sampling locations and radon concentrations at each location

\begin{tabular}{|l|l|l|l|}
\hline Sample & Longitude & Latitude & $\begin{array}{l}\text { Radon } \\
\text { concentration } \\
\left(\mathbf{k B q} / \mathbf{m}^{\mathbf{3}}\right)\end{array}$ \\
\hline L (low) & E36.963413 & N127.4611214 & 3.40 \\
\hline $\mathrm{M}$ (medium) & E36.730596 & N127.7945937 & 46.99 \\
\hline H (high) & E36.739337 & N127.7919314 & 96.97 \\
\hline
\end{tabular}

\section{RESULTS AND DISCUSSION}

In Fig. 2 is shown the graph for experimental result for soil samples for low concentration, medium concentration and high concentration. For the sample soil of low concentration, we obtained the measurement of $14.8 \mathrm{~Bq} / \mathrm{m}^{3}$ for A-1, 37.0 Bq $/ \mathrm{m}^{3}$ for $\mathrm{A}-2$, $90.7 \mathrm{~Bq} / \mathrm{m}^{3}$ for $\mathrm{P}-1,253.5 \mathrm{~Bq} / \mathrm{m}^{3}$ for $\mathrm{P}-2,135.1$ $\mathrm{Bq} / \mathrm{m}^{3}$ for $\mathrm{P}-3$ and $457.0 \mathrm{~Bq} / \mathrm{m}^{3}$ for the Unprotected. For the soil sample of medium concentration, we obtained the measurement of $37.0 \mathrm{~Bq} / \mathrm{m}^{3}$ for $\mathrm{A}-1,66.6$ $\mathrm{Bq} / \mathrm{m}^{3}$ for $\mathrm{A}-2,96.2 \mathrm{~Bq} / \mathrm{m}^{3}$ for $\mathrm{P}-1,299.7 \mathrm{~Bq} / \mathrm{m}^{3}$ for $\mathrm{P}-2,133.2 \mathrm{~Bq} / \mathrm{m}^{3}$ for $\mathrm{P}-3$ and $793.7 \mathrm{~Bq} / \mathrm{m}^{3}$ for Unprotected. For the soil sample of high concentration, we obtained the measurement of $62.9 \mathrm{~Bq} / \mathrm{m}^{3}$ for $\mathrm{A}-1$, 68.5 Bq/m $/ \mathrm{m}^{3}$ for A-2, $146.2 \mathrm{~Bq} / \mathrm{m}^{3}$ for P-1, 299.7 Bq $/ \mathrm{m}^{3}$ for $\mathrm{P}-2,207.2 \mathrm{~Bq} / \mathrm{m}^{3}$ for $\mathrm{P}-3$ and $967.6 \mathrm{~Bq} / \mathrm{m}^{3}$ for Unprotected.

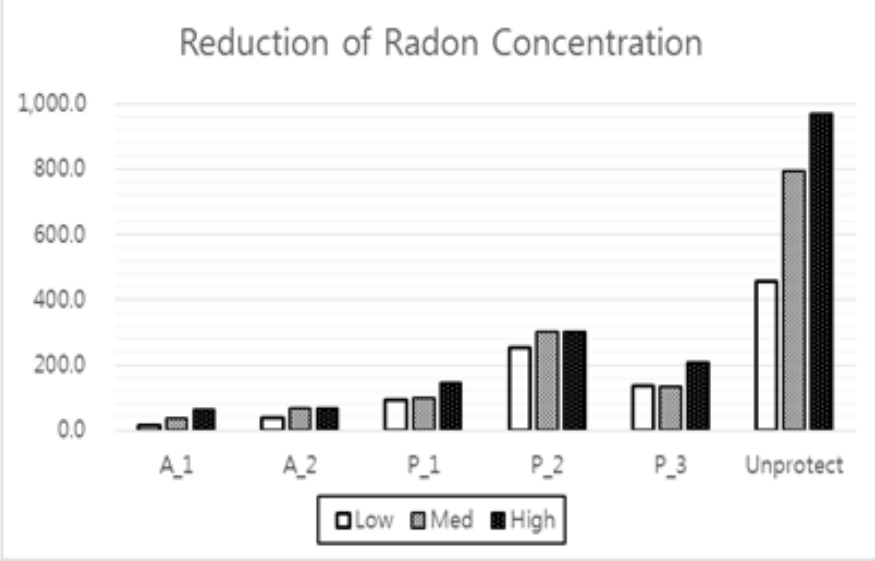

Figure 2: Experimental results for soil samples of three kinds of radon concentrations

From the experimental data, we obtained two observations. The first one is that, radon mitigating materials make much greater effects when they are used in an active mode. This result is in accordance with the EPA recommendations. The best result was from A-1 mode in which case SGMs, ARMs, and a ventilation fan are employed altogether. For all soil samples of low, medium and high concentration, the radon concentration turned out to be the lowest, about $10 \% \sim 40 \%$ of the EAL. In A-2 mode in which case SGMs and a ventilation fan were used, the concentration was a reasonably fair level, about $25 \% \sim 48 \%$ of the EAL. The second observation is that the performance of mitigating materials used in passive modes is unreliable. In all of three passive test modes in which cases no ventilation fan was on, the radon concentration was higher than the EAL, or just below the EAL.

So far, we measured the radon concentration of rooms for six modes in combination of radon mitigating materials for three different soil samples. The main focus of study is on whether the radon concentration of indoor air exceeds the EAL when radon mitigating materials are installed in the substructure of a building. In this paper, another important issue is focused on the efficiency of mitigating materials in each mode. We present an evaluation procedure of the mitigation efficiency of various combination of radon mitigating materials. An objective efficiency of radon mitigating materials is given by RRE (radon reduction efficiency) as shown in eq. (1), which defines the ratio of radon reduction in each of the five modes with reference to the Unprotected case in which no mitigation measures are taken. 
RRE (i) $=($ Unprotected $-\mathrm{i}) /$ Unprotected $* 100(\%)$ (1)

where $\mathrm{i}=\mathrm{A}-1, \mathrm{~A}-2, \mathrm{P}-1, \mathrm{P}-2, \mathrm{P}-3$

Table 3. RRE for the soil samples of three kinds of radon concentrations $(\%)$

\begin{tabular}{|l|l|l|l|l|l|}
\hline & A-1 & A-2 & P-1 & P-2 & P-3 \\
\hline L (low) & 96.8 & 91.9 & 80.2 & 44.5 & 70.4 \\
\hline M (medium) & 95.3 & 91.6 & 87.9 & 62.2 & 83.2 \\
\hline H (high) & 93.5 & 92.9 & 84.9 & 69.0 & 78.6 \\
\hline \hline Average & 95.20 & 92.13 & 84.33 & 58.57 & 77.40 \\
\hline
\end{tabular}

In Table 3 is shown the result of RRE for the five modes based on eq. (1). As shown in Table 3, a radon fan in addition to SGMs (A-2) gives a RRE of $92 \%$. When ARMs are added (A-1), the RRE increases by $3 \%$. However, when the radon fan is off $(\mathrm{P}-1)$, the RRE drops to about mid- $80 \%$ even with SGMs and ARMs. When only ARMs are installed without a radon fan (P-3), we get a RRE of the second half of $70 \%$. At last, when the radon fan is off when only SGMs are installed, the RRE is the lowest of all, the second half of $50 \%$. A comprehensive interpretation of Table 3 is that the most efficient radon mitigation method is using a radon fan. In summary, a radon fan has a large influence on the improvement of radon reduction efficiency. It is the most powerful tool for meeting the EAL, as shown in A-1 and A-2 in Figure 2.

\section{CONCLUDING REMARKS}

Offering homes with radon-resistant features can attract more potential home buyers, which can translate into closing more sales and greater profits. About one in every six homes is being built radonresistant in the United States every year, averaging about 200,000 homes annually, according to annual surveys of home builder practices conducted by the National Association of Home Builders (NAHB) Research Center over the past decade. In high radon areas, about one in every three homes is built with the features.

In this study, we built a model house for the performance analysis of a SGM, an ARM and a radon fan, which are most widely used for radon mitigation. The tests are performed for the radon mitigation in six modes for soil samples of three different radon concentrations. The experimental results show that, in passive modes with a fan off, EAL could be met only in limited cases such that both SGMs and ARMs are installed against soil samples with radon concentration of low or medium level. We could confirm that all the active modes with a radon fan on could meet the EAL. A radon fan is believed to be the most powerful tool for meeting the EAL reference. Therefore, we expect our study to be helpful to the establishment of RRNC code for Korean government.

\section{ACKNOWLEDGMENT}

This work was also supported by the National Research Foundation of Korea (NRF) grant funded by the Korea government (MSIP) (No. 2016011249).

\section{References}

[1] Minkin L and Shapovalov AS, "Indoor radon entry: 30 years later," Iran J Radiat Res, Vol.6, No.1, pp. 1-6, 2008.

[2] Abel-Ghany HA, "Exposure of school children to alpha particles," Iran J Radiat Res, Vol.6, No.3, pp.113-120, 2008

[3] Bouzarjomehri F and Ehrampoosh NH, "Radon level in dwellings basement of Yazd-Iran," Iran J Radiat Res, Vol.6, No.3, pp.141-144, 2008

[4] Sathish LA, Nagaraja K, Ramanna HC, Nagesh V, Sundareshan S, "Concentration of radon, thoron and their progeny levels in different types of floorings, walls, rooms and building materials," Iran J Radiat Res, Vol.7, No.1, pp.1-9, 2009

[5] Hadad K, Hakimdavoud MR, Hashemi-Tilehnoee M, "Indoor radon survey in Shiraz-Iran using developed passive measurement method," Iran J Radiat Res, Vol.9, No.3, pp.175-182, 2011

[6] Verma D, Shakir Khan M, Zubair M, "Measurements of indoor radon, thoron and their progeny in Farrukhabad city of Uttar Pradesh, India," Iran J Radiat Res, Vol.10, No.3-4, pp.193196, 2012

[7] Leghrouz AA, Abu-Samreh MM, Shehadeh AK, "Measurements of indoor radon concentration levels in dwellings in Bethlehem, Palestine," Health Physics, Vol.104, No.2, pp.163-167, 2013

[8] Barros NG, Steck DJ, Field RW, "A comparison of winter short-term and annual average radon measurements in basements of a radon-prone 
region and evaluation of further radon testing indicators," Health Physics, Vol.106, No.5, pp.535-544, 2014

[9] Al-zabadi H, Mallah K, Saffarini G, "Indoor exposure assessment of radon in the elementary schools, Palestine," International Journal of Radiation Research, Vol.13, No.3, pp.221-228, 2015

[10] Fahiminia M, Fouladi-Fard R, Ardani R, Naddafi $\mathrm{K}$, Hassanvand MS, Mohammadbeigi A, "Indoor radon measurements in residential dwellings in Qom, Iran," International Journal of Radiation Research, Vol.14, No.4, pp.331-339, 2016

[11] Alqadi MK, Alzoubi FY, Jaber MA, "Assessment of radon gas using passive dosimeter in Amman and Al-Rusaifa cities, Jordan," International Journal of Radiation Research, Vol.14, No.4, pp.367-371, 2016

[12] Vaupotič J, Smrekar N, Žunić ZS, “Comparison of radon doses based on different radon monitoring approaches," Journal of Environmental Radioactivity, Vol.169-170, pp.19-26, 2017

[13] Vaupotic J, Krizman M, Planinic J, Kobal I, "Radon level reduction in two kindergartens in Slovenia," Health Physics, Vol.66, No.5, pp.568572, 1994

[14] Najafi FT, "Radon reduction systems in the construction of new houses in Gainesville, Florida, “Health Physics, Vol.75, No.5, pp. 514-517, 1998

[15] Coskeran T, Denman A, Phillips P, "The costs of radon mitigation in domestic properties," Health Policy, Vol.57, No.2, pp.97-109, 2001

[16] Denman AR, Phillips PS, Groves-Kirkby CJ,
Crockett RGM, "Do radon-proof membranes reduce radon levels adequately in new houses?," Proceedings of the Seventh SRP International Symposium, 2005 available at http://www.srpuk.org/cardiff05proc.pdf

[17] Denman A, Groves-Kirkby C, Coskeran T, Parkinson S, Phillips P, Tornberg R, "Evaluating the health benefits and cost-effectiveness of the radon remediation programme in domestic properties in Northamptonshire, UK," Health Policy, Vol.73, No.2, pp.139-150, 2005

[18] Synnott H, Colgan PA, Hanley O, Fenton D, "The effectiveness of radon remediation in irish schools," Health Physics, Vol.92, No.1, pp.50-57, 2007

[19] Coskeran T, Denman A, Phillips P, Tornberg R, "The cost-effictiveness of radon-proof membranes in new homes: A case study from Brixworth, Northamptonshire, UK," Health Policy, Vol.81, No.2-3, pp.195-206, 2007

[20] Steck DJ, "The effectiveness of mitigation for reducing radon risk in single-family Minnesota homes," Health Physics, Vol.103, No.3, pp.241248, 2012

[21] Djamil B, "Indoor radon mitigation in South Korea," International Journal of Applied Engineering Research, Vol.11, No.15, pp.85218523, 2016

[22] Young Sub Lee, Yong Hee Lee, Yong Cheol Kim, Gyu-Sik Kim, "Test bed installation for performance evaluation of radon mitigating materials," International Journal of Trend in Scientific Research and Development, Vol. 2, No.3, pp.1613-1617, Mar-Apr, 2018. 